\title{
AN EXPLORATORY ANALYSIS OF FIXED COMMITMENTS IN INDIVIDUAL ACTIVITY-TRAVEL PATTERNS
}

Teresa Frusti, Chandra R. Bhat, and Kay W. Axhausen

\begin{abstract}
This study examines the presence of fixed commitments in the activity-travel patterns of individuals. Data obtained from a 6-week travel diary survey undertaken in Germany is used in the empirical analysis. The results provide several important insights into the determinants of fixed commitments.
\end{abstract}




\section{INTRODUCTION}

Many factors influence activity-travel behavior, including the needs, preferences, and rhythms of a household and its members. This paper examines the rhythms in individual and household activity-travel patterns; specifically, the focus is on understanding the nature of fixed commitments, and the effect of household and individual sociodemographics, social roles, and work-related characteristics on the presence and types of fixed commitments.

The study is motivated by the limited research on fixed commitments, and the critical impact of such commitments in shaping the overall activity-travel patterns of individuals. Fixed commitments are defined as activities that occur on a regular schedule, such as those associated with work, church, or clubs. There are a number of reasons for explicitly recognizing fixed commitments in travel modeling. First, forecasting models typically use number of trips as the dependent variable; trips are dependent on activity-travel behavior, which is in turn influenced by fixed commitments. If fixed commitments are ignored, many of the relevant relationships and correlations between activity behavior and its determinants may be overlooked. Second, when proposing policies, it is important to recognize that a high level of fixed commitments implies less schedule flexibility. For example, consider the case of a father dropping his child at day care before proceeding to work. Since this activity is rather "fixed" in time and space, it is unlikely that the activity-travel pattern of this individual will change after the introduction of auto-use disincentive policies such as parking fees and congestion pricing. Consequently, ignoring fixed commitments of individuals can lead to an overly optimistic picture of the effectiveness of transportation control measures. Third, an understanding of the temporal and spatial rhythms of individuals can inform land use planning by helping to match the supply of activity centers with the demand for such centers.

It should be clear from the above discussion that fixed commitments play an important role in determining travel and activity choice decisions. The current research contributes to a better understanding of fixed commitments in individuals' activity-travel patterns and develops models of fixed commitments that can be used with activity-based travel forecasting systems. The paper is structured as follows. Section 2 reviews the relevant literature. Section 3 describes the data source. Section 4 presents the modeling structure used for examining the presence of fixed commitments. Section 5 discusses the empirical results of the models. Finally, Section 6 summarizes the implications of this research for travel forecasting, planning, and policy making.

\section{BACKGROUND}

Travel demand models typically use trips, not activities, as a basis for behavior. However, transportation researchers have recognized for quite some time now that trips do not capture activity and travel behavior as comprehensively as activity-based models do. In this section, we review the literature on activity-based travel models, with a specific emphasis on earlier research relevant to the subject of fixed commitments. The review is classified under three broad subject areas: 1) Activity-based behavior and time-use behavior, 2) Variability in activity-travel behavior, and 3) Household labor division and grocery shopping behavior.

\section{Activity-Travel Behavior and Time-Use}

In the mid-1970s, the Transport Studies Unit at Oxford University introduced a new paradigm for travel demand modeling; this paradigm, first known as the TSU paradigm, has since evolved into what is known today as the activity-based modeling paradigm of travel forecasting. Activitybased modeling assumes that travel results from participation in activities distributed over space. 
Participation in activities is restricted by three types of constraints: 1) the location of activity facilities, 2) times of day for possible or desirable trips, and 3) availability and cost of vehicles or other means of transportation.

Time-use analysis is a closely related research area that traditionally has been of interest to sociologists seeking to understand how people use their time and the allocation of time to different activities (including in-home activities; see (1)). More recently, the time-use field has also generated substantial interest among transportation modelers in the context of activitybased-travel analysis (see (2), (3) and (4)). Bhat and Koppelman (5) provide a review of the progression of model theory from trip-based models to activity-based models, and most recently time-use studies. Trip-based analyses confine their attention to where and how trips are made. Activity-based analyses study the factors that influence where, how, and why out-of-home activities are pursued, including the needs, preferences, and habits of individuals and households. Time-use research recognizes that travel behavior is based on time-use and activity decisions. Substitution among in-home and out-of-home activities, and the allocation of in-home activities among individuals in a household, plays an important role in determining individual activity travel patterns.

Activity-travel behavior and time-use theories form the basis for considering fixed commitments as determinants of activity-travel patterns, since fixed commitments serve as "pegs" around which other activities are scheduled. Almost all earlier comprehensive activitybased travel frameworks use the concept of fixity in generating the activity-travel systems of individuals. We discuss some of these systems below, and indicate how the concept of fixed commitments is introduced within each of them.

The Prism-constrained Activity-Travel Simulator or PCATS was formulated by Kitamura and Fujii ( 6 ) in 1998 and is based on dividing the day (or any other unit of time) into two types of periods: "open" periods and "blocked" periods. "Open" periods represent times of day when an individual has the option of traveling and engaging in "flexible" activities. "Blocked" periods represent times when an individual is committed to performing "fixed" activities. The determination of what constitutes a "fixed" activity or a "flexible" activity is based on certain assumptions and/or the indication of the survey respondent that certain activities are fixed in time and space. PCATS then attempts to "fill" the open periods based on a space-time prism of activities contained within the open period. Clearly, the underpinning of this framework is based on knowing the fixed activity agenda of individuals (including the fixed activity type and its associated attributes of duration, location, and travel mode to the activity). The explicit modeling of fixed commitments would serve as a substantial enhancement over the procedure of using assumptions to generate the fixed activity agenda.

The framework developed by Bowman and Ben-Akiva (7) employs a discrete choice nested system to model the daily activity-travel schedule of individuals. The system includes choices at the overall daily pattern-level and at the tour-level. The pattern-level choices include three attributes: (1) whether or not to remain home for the entire day, (2) the type of tour involving the "primary" out-of-home activity episode of the day, and (3) the number and purpose of secondary tours. The Bowman and Ben-Akiva (BB) model system is fundamentally based on designating activities as "primary" and "secondary" activities. This designation is based on the purpose of the activity: work activity is assigned the highest priority, followed by work-related, school, and all other purposes. Within a particular purpose, activities with longer durations are assigned higher priorities. The tour of the day with the highest priority activity is designated as the primary tour and others are designated as secondary tours. Within each tour, all activities are 
ranked by priority and the attributes of the primary activity in the tour form the basis for modeling of tours. As should be clear from above, the BB system is critically dependent upon providing the entire agenda of activities by purpose and priority as input. Currently, the BB system uses deterministic and simple rules to define activity priority. A better approach would be to determine the fixity of activities in an individual's agenda based on a formal model of fixed commitments, and then use this to designate priorities in forecasting activity-travel patterns.

Bhat and his coworkers (see (8), (9), and (10)) have developed the "Comprehensive Econometric Microsimulator for Generating Daily Activity-Travel Patterns" (or CEMDAP) system that models the entire activity-travel patterns of individuals along a continuous-time domain. The framework considers time as an all-encompassing continuous entity in analysis and includes generation of activity stops by purpose as well all scheduling aspects of an individual's daily activity-travel pattern. The CEMDAP framework emphasizes spatial and temporal detail, while also providing an overarching structure to allow interactions in activity and travel across different times of the day. The framework develops separate modules for worker and nonworker activity travel patterns, recognizing that the underlying factors influencing the travel-related decisions of nonworkers and workers are quite different. The worker framework (labeled as the Comprehensive Activity-Travel Generation System for Workers, or CATGW) and the nonworker framework (labeled as the Comprehensive Activity-Travel Generation System for Nonworkers, or CATGNW) do not need the designation of an activity as a "fixed" or "flexible". Both frameworks identify a number of different activity-based attributes within a pattern, based on the level of representation the attributes are associated with: that is, whether they are associated with the entire daily pattern, a tour in the pattern, or an individual episode. The analysis approach is based on modeling the pattern-level attributes first, followed by the tourlevel attribute of mode choice, and finally the episode-level attributes. Within each tour the sequence of stops is modeled implicitly by determining the characteristics of the first stop, then the second conditional on the first, the third conditional on the first two, and so on. This procedure would be considerably enhanced by a procedure that determines the fixity of each activity stop and models the sequence of stops based on the fixity level of each stop, starting with the activity episode with the highest fixity level. Toward this end, a formal model of fixed activity commitments would aid in the implementation of the CEMDAP activity framework.

In addition to the comprehensive frameworks discussed above, several modeling efforts have focused on activity scheduling models using a computerized production system framework that comprises a set of rules in the form of condition-action pairs. All of these scheduling models assume the presence of an initial agenda of activities and their attributes, along with a priority designation for each activity. The determination of the final activity schedule for an individual is based on the priority designations. For example, Garling et al. (11) proposed an activity scheduling model labeled SCHEDULER that assumes the presence of a long term calendar (an agenda of activity episodes with duration, appointment details and preference) at the start of any time period. A small set of episodes with high priority is selected from this long term "calendar" and stored in a short term calendar as the subset of episodes to be executed in the short-run. This activity subset is sequenced, and activity locations determined based on a "distance-minimizing" heuristic procedure. Ettema et al. (12) further develop the SCHEDULER model by specifying and testing alternative heuristic scheduling rules within the SCHEDULER framework. More recently, Arentze et al. (13) have developed the ALBATROSS model, also based on the concept of generating a schedule around constraints imposed by "fixed" activities, and associated logical, temporal, and spatial attributes of the fixed activities. In all of these scheduling models, 
designating priorities or the level of commitment is critical. Most of these scheduling models, however, assume the level of fixity of activities to be exogenously provided. In actual implementation, the level of fixity of each activity has to be estimated for use in forecasting, which again highlights the importance of models of fixed commitments.

The discussion above indicates the critical need for models of fixed commitments in forecasting activity-travel patterns.

\section{Variability in Activity-Travel Behavior}

Huff and Hanson, in a sequence of papers in the mid to late 80s (see (14) and (15)), have shown that certain specific attributes of an individual's activity-travel pattern (such as the mode and start time for work trips) may be routine and repetitive. However, the overall daily patterns of individuals (including activities and sequencing) vary considerably day to day, even on weekdays. The papers by Huff and Hanson hypothesize that if activity patterns are not repetitive on a day-to-day basis, they may at least be more repetitive at some longer interval. To examine this hypothesis, the researchers classify variations in activity-travel behavior between and within individuals into interpersonal random, interpersonal non-random, intrapersonal random, and intrapersonal non-random. Since intrapersonal variability cannot be determined from a one-day study, the researchers use the five-week Uppsala travel diary in their analysis. Huff and Hanson's results suggest that activity-travel patterns of individuals may vary from being completely random at one extreme (where decisions are made independently for each trip and there is no pattern), to being totally habitual on the other (where individuals participate in the same activity at the same destination by the same mode every day). However, they point out that the activitytravel patterns of most individuals do not fall in these extremes. Instead, the patterns of most individual exhibit a mixture of variability as well as habit; variability because of preference for variety and unpredictable events, and habits for easier interactions with others and easier decision-making.

In a related study, Pas and Koppelman (16) examined the determinants of day-to-day variability using a five-day travel diary collected in Reading, England. They indicate that examining day-to-day variability in travel behavior is important because it affects daily travel peaks, and may affect the analysis of transportation policy options. Their analysis showed that individuals with more constraints in their activity-travel patterns have less intrapersonal variability.

The discussion above emphasizes the importance of examining variability in activitytravel behavior across individuals (interpersonal variability) and across days for the same individual (intrapersonal variability). Fixed commitments determine the level of intrapersonal variability, as indicated by Pas and Koppelman (16). Consequently, a study of fixed commitments is critical to quantifying intrapersonal variability and the resulting impacts on travel forecasting.

\section{Grocery Shopping Behavior and Household Labor Division}

Grocery shopping has been analyzed extensively because of its regularity over extended periods of time (such as a week or a month) and the importance of such regular patterns for travel modeling and marketing analysis. Doti and Sharir (17) were among the first to study the effect of household characteristics on grocery shopping behavior. Blaylock (18) extended Doti and Sharir's study by developing economic formulations for the frequency of grocery shopping, as well as the effect of household characteristics on frequency. Kim and Park (19) discussed the 
motivations of irregular shoppers compared to regular shoppers, and developed a model to distinguish between the shopping behaviors of these two kinds of shoppers.

Household labor division has been of substantial interest in several fields, including economics, sociology, and transportation. This area is important to our study of fixed commitments, since most household maintenance activities that are allocated among household members are relatively mandatory and less flexible than leisure and recreational activities. There are three general theories of labor division within a household. The first, the time availability theory, assumes that the partner with more available time will undertake a larger share of household labor. The second, the power theory, states that the partner who earns more money has more influence in decision making. Finally, the gender role theory hypothesizes that men and women are likely to do chores based on gender-identified roles assigned by society, and that in doing so they perpetuate the idea of their genders (for example, women do "women's work" in order to teach their daughters, and because society expects it). These theories are explored by Blair and Lichter (20), Brines (21), and Mederer (22). Spitze (23) examines the sources of housework, including outside help, and Shelton and John (24) determines if marital status is a significant factor in household labor division.

As indicated earlier, grocery shopping and household labor are two examples of activities in which individuals typically participate on a regular basis, and which are often fixed commitments. Insights into these types of fixed commitments would provide a stronger understanding of overall behavior and of specific activities, such as recreation, work, and shopping.

To summarize, fixed commitments play an important role in understanding the activitytravel patterns of individuals, and in facilitating improved travel forecasting and transportation policy analyses (see also Axhausen (25)). However, the subject of fixed commitments has received relatively little attention in the transportation literature. The few earlier studies on this topic focus on one type of fixed commitment, such as shopping or work trips. This research attempts to tie concepts from earlier research in several fields to understand the presence and type of fixed commitments in individual activity-travel patterns.

\section{DATA}

The data for this research is obtained from a 6-week continuous travel diary administered in 1999 to 361 individuals in 162 households as part of a larger Mobidrive project, sponsored by the Federal Republic of Germany Ministry of Research and Education, and intended to better understand travel patterns in Germany (26). Participants in the survey were drawn from the resident population in the German cities of Karlsruhe and Halle. The survey was administered as a pretest in Karlsruhe and two 6-week main survey waves in Halle and Karlsruhe. The waves overlapped by a few weeks, with a total spread of 9 weeks in Halle and 10 weeks in Karlsruhe. The waves were separated in order to accommodate seasonal variations in activity-travel patterns, as well as to avoid the Christmas and summer holidays. Households were not included if they had children 6 years old or younger, or if a vacation longer than one week was planned. Slightly less than $10 \%$ of the total sample (approximately $15 \%$ of eligible households) participated. Basic information on non-participating households was collected, and research by Axhausen et. al. (26) has revealed no significant self-selection or fatigue effects.

The survey comprised three parts. First, a face-to-face interview was administered where the interviewer assisted the household in filling out three forms (corresponding to household, personal, and vehicle information). Second, a 7-day travel diary was sent weekly to each 
household and individuals in the household were asked to maintain a record of all their trips and out-of-home activities over a 6-week period. Finally, an attitude questionnaire was administered to participants at least 16 years old once the final week's diary had been turned in; although households were not required to complete it, approximately $90 \%$ responded (26).

The purpose of the study was to collect data on activity-travel patterns of individuals over an extended period of several weeks to enable accurate travel forecasting, as well as to study rhythms in daily and weekly activity patterns more effectively (26). The Mobidrive data is unique. Before the Mobidrive project, the longest travel diary administered was a five-week travel diary in Uppsala in 1971, which is now outdated. Also, the Uppsala data set does not provide all the necessary information for observing activity rhythms and variability.

Table 1 provides basic descriptive statistics of the Mobidrive sample. As can be observed in Table 1, approximately $50 \%$ of individuals are married, employed, and male. Only $21 \%$ are students, which logically corresponds with the $25 \%$ of individuals who are not adults (an adult is defined as an individual whose age is equal to or greater than 16 years). In terms of household structure, approximately the same number of households are single adults, couples, or nuclear. A nuclear household has two household heads of opposite sex, with one or more children. All other households are classified in the "other" category, including single parent households (one household head and at least one child under 16 years old), returning young adult households (two household heads, and all individuals are older than 21 years old), extended family (includes young adult and elderly individuals as household heads), adult and aged parent (one adult and one older adult), and roommates (two or more adults of same gender, and no children under age 16).

\section{MODEL FORMULATION}

The original survey form sought information on six types of fixed commitments: club-related activities, political party activities, volunteering, training, care for outside person, and support outside home. Respondents also had the opportunity to indicate their fixed commitments in an "other" category. The total number of responses included 22 different activities. These were organized into five general categories in our analysis: recreational, personal, community, training, and other. The mapping we used to classify the disaggregate activity types into the more aggregate five-activity typology is provided in Table 2 .

The empirical focus of the current paper is on examining the presence of fixed commitments by the activity typology in Table 2 , and the overall presence of fixed commitments across all activity types. To pursue such an analysis, we defined dummy variables indicating the presence or absence of fixed commitments. This was followed by an informal descriptive analysis of the level of fixed commitments among respondents, and cross-tabulations of the fixed commitment levels with individual sociodemographic variables. Finally, more formal binary logit formulations were used to examine the sociodemographic determinants of fixed commitments. The next section discusses the results of our descriptive analysis, and Section 4.2 presents the results of the binary logit models.

\subsection{Descriptive Analysis}

The percentage of individuals having each type of fixed commitment is shown in Table 3 . As can be observed in Table 3, a very small fraction of individuals in the data have training fixed commitments and "other" fixed commitments. Hence, the focus of the modeling efforts in the 
current paper is on examining fixed commitments only in the first four categories (overall, recreational, personal, and community fixed commitments).

Table 4 provides the percentage of individuals in each of eight groups (corresponding to four segmentation variables) who have a fixed commitment in the four fixed commitment categories identified above. The results for gender show that there is a relatively equal percentage of men and women participating in each type of fixed commitment. The results for adult status show that children have more fixed commitments in all categories, except community-related activities. As expected, students had approximately the same trends as children. Finally, individuals who are not employed have more fixed commitments than those who are employed, except for community activities.

\subsection{Binary Logit Models}

We estimated four binary logit models, one for each of the four types of fixed commitments (general, recreational, community, and personal). Thus, the first model analyzed the overall presence of fixed commitments; the second model examined the presence of recreational fixed commitments; and so on. The models had the following structure:

$$
P\left(y_{i n}=1\right)=\frac{1}{1+e^{-\beta_{i}^{\prime} X_{i n}}}
$$

where $i$ is an index for fixed commitment type, $n$ is an index for individual, $y_{i n}$ is a dummy indicator for the presence of a fixed commitment of type $i$ in the activity-pattern of individual $n$, $X_{\text {in }}$ is a vector of individual-related attributes affecting the presence of fixed commitments of type $i$, and $\beta_{i}$ is a vector of coefficients corresponding to fixed commitments of type $i$. The binary logit model estimates the coefficient vector $\beta_{i}$ using the maximum likelihood method (see BenAkiva and Lerman; Chapter 4 (27)).

\section{RESULTS}

Three broad categories of variables were included in the empirical analysis: (a) personal demographics, (b) household characteristics, and (c) spouse-related characteristics. Personal characteristics explored in our specifications included dummy variables for gender, employment status, adult status, marital status, license holding and education level, and continuous variables for age, work hours and number of course hours per week. In addition, gender-based interactions with other personal demographic characteristics were also considered. Household characteristics considered in the specifications included household income, household size, and type of family structure (single adult, nuclear family, etc.). Finally, the spouse-related characteristics examined in the analysis mirrored the personal characteristics listed above.

The final specification was based on a systematic process of specification testing in which new variables were added to the model with only a constant, and those variables that were statistically significant and intuitive in their effects were finally retained (however, in a few cases, we retained coefficients even if they were statistically insignificant because of the intuitive direction of their effects and in consideration of the small sample size used in the analysis). The results are presented in Table 5. A '--' in a column indicates that the corresponding variable did not have a statistically significant effect. 
The constants do not have any behavioral interpretation. They capture unobserved biases toward fixed commitments as well as the range of exogenous variables included in the model. The effects of the remaining variables are discussed by variable category below.

\subsection{Personal Sociodemographics}

Table 5 reveals that very few variables in the personal demographic category have a consistent effect across fixed commitment types. The results show an increase in age has a positive effect on the likelihood of an individual having general or personal fixed commitments. Married individuals are more likely to have fixed commitments in general, and community fixed commitments in particular. This may reflect the joint nature of activity participations of married individuals; information is not available at this time concerning joint activities. Individuals who are parents are more likely to have recreational fixed commitments. This may reflect the need to transport or supervise children while the kids participate in recreational activities.

Student status is the most significant indicator in all models except community activities. This is logical, since school typically ends by 1:00 pm in Germany and so students have time to participate in clubs and sports. The number of course hours refers to those who are taking individual courses, such as night school. As expected, those with a larger number of course hours are less likely to have fixed commitments, especially recreational fixed commitments. This may reflect the fact that those taking courses have less free time.

\subsection{Household Sociodemographics}

Household income increases the chance of having recreational and personal fixed commitments, and fixed commitments in general. In these models, households have been categorized into four aggregate categories: single, couple, nuclear, and "other". Each model uses individuals in single households as the base. The results show that for all types of fixed commitments, individuals in non-single households have a lower likelihood of fixed commitments. The effect of the final variable under household demographics indicates that individuals in larger households have fewer fixed commitments. The exception is personal fixed commitments, where an increase in members in the household results in a larger likelihood of personal fixed commitments.

\subsection{Spouse Variables}

In a number of previous studies, it has been shown that the propensity for an individual to undertake a specific action (for example, household labor division) is often related to the gender and other sociodemographics of his or her spouse. However, in general, this is not the case for fixed commitments. An individual with an older spouse is less likely to have fixed commitments. Individuals with employed spouses or spouses with a university education have a lower likelihood of recreational fixed commitments.

\section{SUMMARY AND CONCLUSIONS}

This study examines the presence of fixed commitments in the activity-travel patterns of individuals. Data obtained from a 6-week travel diary survey undertaken in Germany is used in the empirical analysis. The results provide several insights into the determinants of fixed commitments. Specifically, the results indicate that if there are more people in an individual's household, the individual is more likely to have fixed commitments (reflected in the variables Parent and Married). This could be because caring for more family members results in the production of more maintenance-related activities. Another explanation is that as a person needs 
to work around more schedules, it becomes necessary to plan activities more carefully compared to an individual living alone. For example, an individual may decide to have lunch on a fixed schedule each day so that she or he can go home or meet a family member for dinner; if the individual lived alone, she or he would be more likely to have lunch at different times depending on the other activities of that day. The results also show that students are more likely to have fixed commitments than non-students, except for community fixed commitments. This is understandable, since students do not have school in the afternoon and so have more time for activities such as sports or clubs. These activities generally have a fixed time and location. Finally, some of the results may reflect the need to transport/supervise children during the kids' participation in recreational activities.

The current paper focuses on an exploratory analysis of fixed commitments. Obviously, this is just a starting point for further research in this area. However, even in its current exploratory form, the results from this model can be incorporated in an activity-travel forecasting system. To be specific, consider the modeling systems discussed in Section 2. Fixed commitments appear in the frameworks of these systems in one of two ways. In the PCATS system, the agenda of fixed activities is established first, and this fixed activity agenda is then used as a "skeleton" around which other flexible activities are generated and scheduled. In all the other systems, the activity-travel scheduling structure revolves around assigning priorities to a comprehensive agenda of activity episodes that have already been generated. The models developed in this paper are of limited use for application with the PCATS structure, since detailed information on the number and attributes of fixed commitments (such as duration and time of day) are not analyzed here (this is because the German data set used in the current analysis did not collect such data). However, the models developed in the current paper can be readily embedded within the structure of the other systems. The approach would involve the following three steps. First, estimate the probability of each type of activity being a fixed commitment based on the models developed in the paper, and the personal demographics and household characteristics of each individual in the forecast scenario. Second, for each activity episode in each individual's already-generated activity agenda, do the following: (1) Determine the probability of the episode being a fixed commitment based on the purpose-specific fixed commitment probabilities estimated in the previous step and the purpose of the episode, (2) Partition the unit interval into two segments: the first segment should extend from 0 to the estimated probability of fixed commitment for that episode, and the second segment should extend from the estimated probability of fixed commitment to 1, (3) Draw a random number from the uniform distribution, (4) If the random number falls in the first segment, declare the episode as a fixed commitment and retain the value of the random number, (5) If the random number falls in the second segment, declare the episode as a non-fixed commitment and retain the length of the portion of the second segment from the partition point to the random number. Third, to assign priorities among all activity episodes in the activity agenda of an individual, do the following: (6) Arrange the episodes designated as fixed commitments in descending order of their corresponding random numbers, (7) Arrange the episodes designated as non-fixed commitments in ascending order of their lengths from part (5), (8) Concatenate the episode listings from (6) and (7), preserving the ordering and placing the listing from (7) after the listing from (6), (9) Number the episodes in the order they appear in this combined listing, and use these numbers as the priority rankings (the first episode is the one with highest priority and the last one is the one with lowest priority). This entire procedure can be very easily implemented within a simulation environment for use with the modeling systems discussed in Section 2. 
In closing, we would like to emphasize that the empirical results from the study have important implications for transportation policy analysis and travel modeling. Most fixed commitments are inflexible in destination, time of day, mode, and decision to make a trip. In forecasting, modelers are likely to overestimate the impact of policy changes if they ignore such fixed commitments, since individuals are unlikely to change fixed commitments and associated activity attributes. This includes mode shifts, such as transit ridership from transit incentive or auto disincentive policies, and time shifts, such as the reduction of traffic on roads during peak hours from congestion pricing or HOT lanes.

\section{ACKNOWLEDGEMENTS}

The authors would like to thank Stefan Schönfelder for providing the Mobidrive data used in the current study, and for clarifying data-related issues. Robert Schlich and Arnd König contributed to the data generation process. Lisa Weyant helped with formatting and typesetting. Three anonymous reviewers provided valuable comment on an earlier version of this paper. This research was partially funded by a Southwest Region University Transportation Center grant. The authors are grateful for the access to data provided by the Mobidrive Consortium (PTV AG, Karlsruhe, Institut für Stadtbauwesen, RWTH Aachen and the IVT, ETH Zürich). The project was funded by the German Ministry of Research and Technology. 


\section{REFERENCES}

1. Pas, E.I., and A.S. Harvey. Time Use Research and Travel Demand Analysis Modeling. In P.R. Stopher and M.E.H. Lee-Gosselin (eds.) Understanding Travel Behavior in an Era of Change, Pergamon, Oxford, 1997, pp. 315-338.

2. Pas, E.I. Weekly Travel-Activity Behavior. Transportation, Vol. 15, No. 1/2, 1988, pp. 89109.

3. Bhat, C.R. and R. Misra. Discretionary Activity Time Allocation of Individuals Between InHome and Out-of-Home and Between Weekdays and Weekends. Transportation, Vol. 26, No. 2, 1999, pp. 193-209.

4. Misra, R. and C.R. Bhat. Activity-Travel Patterns of Non-Workers in the San Francisco Bay Area: An Exploratory Analysis, The University of Texas at Austin, 1999.

5. Bhat, C.R. and F.S. Koppelman. A Retrospective and Prospective Survey of Time-Use Research. Transportation, Vol. 26, No. 2, 1999, pp. 119-139.

6. Kitamura, R. and S. Fuji. Two Computational Process Models of Activity-Travel Behavior. In T. Garling, T. Laitila and K. Westin (eds.) Theoretical Foundations of Travel Choice Modeling, Elsevier Science, Oxford, 1998, pp. 251-279.

7. Bowman, J.L. and M.E. Ben-Akiva. Activity-based Disaggregate Travel Demand Model System with Activity Schedules. Transportation Research-A, Vol. 35, No. 1, 2001, pp. 1-28.

8. Bhat, C.R. and S.K. Singh. A Comprehensive Daily Activity-Travel Generation Model System for Workers. Transportation Research-A, Vol. 34, No. 1, 2000, pp. 1-22.

9. Bhat, C.R. and R. Misra. A Comprehensive Activity-Travel Pattern Modeling System for Non-Workers with Empirical Focus on the Organization of Activity Episodes. Paper submitted to Transportation Research Record, 2001.

10. Misra, R. and C.R. Bhat. A Comprehensive Econometric Micro-Simulator for Generating the Daily Activity-Travel Patterns of Non-Workers. Paper presented at the $9^{\text {th }}$ International Association for Travel Behavior Research Conference, The Gold Coast, Australia, July 2000.

11. Gärling, T., K. Brannas, J. Garvill, R.G. Golledge, S. Gopal, E. Holm and E. Lindberg (1989). Household Activity Scheduling. In Transport Policy, Management \& Technology Towards 2001: Selected Proceedings of the Fifth World Conference on Transport Research, Western Periodicals, Ventura, California, Vol. IV, pp. 235-248.

12. Ettema, D., A.W.J. Borgers and H.J.P. Timmermans. Simulation Model of Activity Scheduling Behavior. Transportation Research Record, Vol. 1413, 1993, pp. 1-11.

13. Arentze, T.A., Hofman, F., Van Mourik, H. and H.J.P. Timmermans. Albatross: A MultiAgent Rule-Based Model of Activity Pattern Decisions. Paper presented at the $79^{\text {th }}$ Annual Meeting of the Transportation Research Board, Washington D.C., January 9-13, 2000.

14. Huff, J.O. and S. Hanson. Repetition and Variability in Urban Travel. Geographic Analysis, Vol. 18, No. 2, 1986, pp. 97-114.

15. Hanson, S. and J. Huff. Systematic Variability in Repetitious Travel. Transportation, Vol. 15, No. 1/2, 1988, pp. 111-135.

16. Pas, E.I. and F.S. Koppelman. An Examination of the Determinants of Day-to-Day Variability in Individuals' Urban Travel Behavior. Transportation, Vol. 13, No. 2, 1987, pp. 183-200.

17. Doti, J.L. and S. Sharir. Household's Grocery Shopping Behavior in the Short Run. Economic Inquiry XIX, 1981, pp. 196-208.

18. Blaylock, J.R. An Economic Model of Grocery Shopping Frequency. Applied Economics, Vol. 21, 1989, pp. 843-852. 
19. Kim, B. and K. Park. Studying Patterns of Consumer's Grocery Shopping Trip. Journal of retailing, Vol. 73, No. 4, 1997, pp. 501-517.

20. Blair, S.L. and D.T. Lichter. Measuring the Division of Household Labor. Journal of family issues, Vol. 12, No. 1, 1991, pp. 91-113.

21. Brines, J. Economic Dependency, Gender, and the Division of Labor at Home. American Journal of Sociology, Vol. 100, No. 3, pp. 652-688.

22. Mederer, H.J. Division of Labor in Two-Earner Homes. Journal of Marriage and the Family, Vol. 55, pp. 133-145.

23. Spitze, G. Getting Help with Housework, Journal of Family Issues. Vol. 20, No. 6, 1999, pp. 724-745.

24. Shelton, B.A. and D. John. Does Marital Status Make a Difference?. Journal of Family Issues, Vol. 14, No. 3, 1993, pp. 401-420.

25. Axhausen, K.W. The Design of Environmentally Aware Travel Diaries. Transportation Planning and Technology, Vol. 19, No. 3, 1996, pp. 275-290.

26. Axhausen, K.W., Z. Zimmerman, S. Schönfelder, G. Rindsfuser, and T. Haupt. Observing the Rhythms of Daily Life: A Six Week Travel Diary. Paper submitted to Transportation, 2000.

27. Ben-Akiva, M.E. and S.R. Lerman. Discrete Choice Analysis: Theory and Application to Travel Demand. The MIT Press, Cambridge, 1985. 
Frusti, Bhat, and Axhausen

\section{LIST OF TABLES}

TABLE 1 Sample characteristics

TABLE 2 Aggregate activity categories

TABLE 3 Percent fixed commitments

TABLE 4 Percentage of each sociodemographic population group with fixed commitments TABLE 5 Model results 
Frusti, Bhat, and Axhausen

TABLE 1 Sample Characteristics

\begin{tabular}{|l|c|c|c|}
\hline Variable (dummy) & $\begin{array}{c}\text { Mean } \\
(\mathbf{\%})\end{array}$ & $\begin{array}{c}\text { Minimum } \\
(\mathbf{\%})\end{array}$ & $\begin{array}{c}\text { Maximum } \\
(\mathbf{\%})\end{array}$ \\
\hline Married $(1=$ married, $0=$ not married) & 50.42 & 0 & 100 \\
\hline Employed $(1=$ employed, $0=$ non-employed) & 51.80 & 0 & 100 \\
\hline Male $(1=$ male, $0=$ female) & 49.86 & 0 & 100 \\
\hline Student $(1=$ student, $0=$ non-student) & 21.05 & 0 & 100 \\
\hline Adult $(1=$ adult, $0=$ non-adult $)$ & 74.52 & 0 & 100 \\
\hline Parent $(1=$ parent, $0=$ non-parent $)$ & 31.86 & 0 & 100 \\
\hline
\end{tabular}

\begin{tabular}{|l|c|}
\hline Household structure & $\begin{array}{c}\text { Number of } \\
\text { households }\end{array}$ \\
\hline \hline Single adult & 51 \\
\hline Couple: 1 male adult, 1 female adult (married or cohabiting), no kids & 50 \\
\hline Nuclear: 2 household heads $(1$ male, 1 female) and one or more kids & 51 \\
\hline Other & 10 \\
Single parent: 1 adult, $\geq 1$ child $(<16)$ & 1 \\
Returning young adult: all individuals $>21,2$ household heads & 5 \\
Extended family & 1 \\
Adult and aged parent: $\geq 1$ adult and 1 older adult & 1 \\
Roommate: 2 adults, not married, no children $<16$ & 2 \\
\hline \hline
\end{tabular}


Frusti, Bhat, and Axhausen

TABLE 2 Aggregate Activity Categories

\begin{tabular}{|c|c|c|c|c||}
\hline \hline Recreation & Personal & Community & Training & Other \\
\hline \hline Sports & Church & Community & Training/education & Other \\
\hline Music & Garden & Volunteer & Spanish & \\
\hline Cards & Club & Care for outside person & Speech & \\
\hline Sauna & Political party & Support outside home & & \\
\hline Dance & Doctor & & & \\
\hline Theater & Therapy & & & \\
\hline & Workshop & & & \\
\hline & Meeting & & & \\
\hline
\end{tabular}


Frusti, Bhat, and Axhausen

TABLE 3 Percent Fixed Commitments

\begin{tabular}{|l|c|c|c|c|c|c|}
\hline $\begin{array}{l}\text { Type of fixed } \\
\text { commitment }\end{array}$ & Overall & Recreational & Personal & Community & Training & Other \\
\hline \hline $\begin{array}{l}\text { Percent having no } \\
\text { fixed commitment }\end{array}$ & $55 \%$ & $90 \%$ & $71 \%$ & $92 \%$ & $97 \%$ & $99 \%$ \\
\hline $\begin{array}{l}\text { Percent having at } \\
\text { least one fixed } \\
\text { commitment }\end{array}$ & $45 \%$ & $10 \%$ & $29 \%$ & $8 \%$ & $3 \%$ & $1 \%$ \\
\hline
\end{tabular}


Frusti, Bhat, and Axhausen

TABLE 4 Percentage of Each Sociodemographic Population Group With Fixed Commitments

\begin{tabular}{|l|c|c|c|c|c|c|c|c||}
\hline \multirow{2}{*}{$\begin{array}{l}\text { Commitment Type } \\
\text { (\% of total individuals) }\end{array}$} & \multicolumn{7}{|c||}{ Segmentation Variables } \\
\cline { 2 - 9 } & Male & Female & Adult & Child & Student & $\begin{array}{c}\text { Non- } \\
\text { student }\end{array}$ & Employed & $\begin{array}{c}\text { Not } \\
\text { employed }\end{array}$ \\
\hline \hline $\begin{array}{l}\text { Overall fixed } \\
\text { commitment }\end{array}$ & $43 \%$ & $46 \%$ & $40 \%$ & $59 \%$ & $72 \%$ & $38 \%$ & $39 \%$ & $52 \%$ \\
\hline $\begin{array}{l}\text { Recreational fixed } \\
\text { commitment }\end{array}$ & $9 \%$ & $12 \%$ & $8 \%$ & $16 \%$ & $20 \%$ & $8 \%$ & $7 \%$ & $14 \%$ \\
\hline $\begin{array}{l}\text { Personal fixed } \\
\text { commitment }\end{array}$ & $29 \%$ & $29 \%$ & $25 \%$ & $42 \%$ & $51 \%$ & $23 \%$ & $25 \%$ & $33 \%$ \\
\hline $\begin{array}{l}\text { Community fixed } \\
\text { commitment }\end{array}$ & $7 \%$ & $9 \%$ & $10 \%$ & $4 \%$ & $5 \%$ & $9 \%$ & $9 \%$ & $8 \%$ \\
\hline No fixed commitment & $57 \%$ & $54 \%$ & $60 \%$ & $41 \%$ & $28 \%$ & $62 \%$ & $61 \%$ & $48 \%$ \\
\hline \hline
\end{tabular}


TABLE 5 Model Results

\begin{tabular}{|c|c|c|c|c|c|c|c|c|}
\hline \multirow[t]{2}{*}{ Variables ("b" = base) } & \multicolumn{2}{|c|}{$\begin{array}{c}\text { General Fixed } \\
\text { Commitments } \\
\text { Model }\end{array}$} & \multicolumn{2}{|c|}{$\begin{array}{c}\text { Recreational } \\
\text { Fixed } \\
\text { Commitments } \\
\text { Model } \\
\end{array}$} & \multicolumn{2}{|c|}{$\begin{array}{c}\text { Personal Fixed } \\
\text { Commitments } \\
\text { Model }\end{array}$} & \multicolumn{2}{|c|}{$\begin{array}{c}\text { Community } \\
\text { Fixed } \\
\text { Commitments } \\
\text { Model }\end{array}$} \\
\hline & Coeff. & t-stat & Coeff. & t-stat & Coeff. & t-stat & Coeff. & t-stat \\
\hline Constant & -1.772 & -2.807 & -3.393 & -5.847 & -2.394 & -4.253 & -3.018 & -5.222 \\
\hline \multicolumn{9}{|l|}{ Personal Demographics } \\
\hline Age & 0.026 & 2.220 & -- & -- & 0.021 & 1.977 & -- & -- \\
\hline Married $(\mathrm{b}=$ nonmarried $)$ & 0.451 & 0.840 & 0.376 & -0.616 & -0.366 & -1.132 & 1.597 & 3.137 \\
\hline Parent $(\mathrm{b}=$ non-parent $)$ & 0.862 & 1.464 & 1.787 & 1.856 & -- & -- & -- & -- \\
\hline Student $(\mathrm{b}=$ non-student $)$ & 2.954 & 4.822 & 2.437 & 2.690 & 1.464 & 3.410 & -- & -- \\
\hline Number of course hours & -0.023 & -1.529 & -0.062 & -2.670 & -- & -- & -- & -- \\
\hline \multicolumn{9}{|c|}{ Household Characteristics } \\
\hline Household income & 0.250 & 3.659 & 0.459 & 4.194 & 0.158 & 1.836 & -- & -- \\
\hline \multicolumn{9}{|l|}{ Type of household } \\
\hline Couple $(b=$ single $)$ & -1.218 & -2.602 & -1.078 & -1.488 & -0.618 & -1.809 & -2.723 & -3.296 \\
\hline Nuclear $(b=$ single $)$ & -1.353 & -2.123 & -1.952 & -2.053 & -- & -- & -3.333 & -2.728 \\
\hline Other $(b=$ single $)$ & -2.336 & -3.109 & -3.164 & -2.490 & -0.987 & -1.836 & -3.687 & -2.577 \\
\hline $\begin{array}{l}\text { Number of household } \\
\text { members }\end{array}$ & -- & -- & -- & -- & -- & -- & 0.797 & 2.308 \\
\hline \multicolumn{9}{|l|}{ Spouse Variables } \\
\hline Spouse's age & -0.017 & -1.804 & -- & -- & -- & -- & -- & -- \\
\hline Spouse is employed & -- & -- & -3.438 & -3.296 & -- & -- & -- & -- \\
\hline $\begin{array}{l}\text { Spouse has university } \\
\text { education }\end{array}$ & -- & -- & -0.963 & -1.181 & -- & -- & -- & -- \\
\hline \multicolumn{9}{|l|}{ Model Statistics } \\
\hline Log likelihood at zero & \multicolumn{2}{|c|}{-248.327} & \multicolumn{2}{|c|}{-119.320} & \multicolumn{2}{|c|}{-217.654} & \multicolumn{2}{|c|}{-103.348} \\
\hline $\begin{array}{l}\text { Log likelihood of final } \\
\text { model }\end{array}$ & \multicolumn{2}{|c|}{-214.898} & \multicolumn{2}{|c|}{-96.733} & \multicolumn{2}{|c|}{-200.897} & \multicolumn{2}{|c|}{-94.325} \\
\hline Number of observations & \multicolumn{2}{|c|}{361} & \multicolumn{2}{|c|}{361} & \multicolumn{2}{|c|}{361} & \multicolumn{2}{|c|}{361} \\
\hline
\end{tabular}

